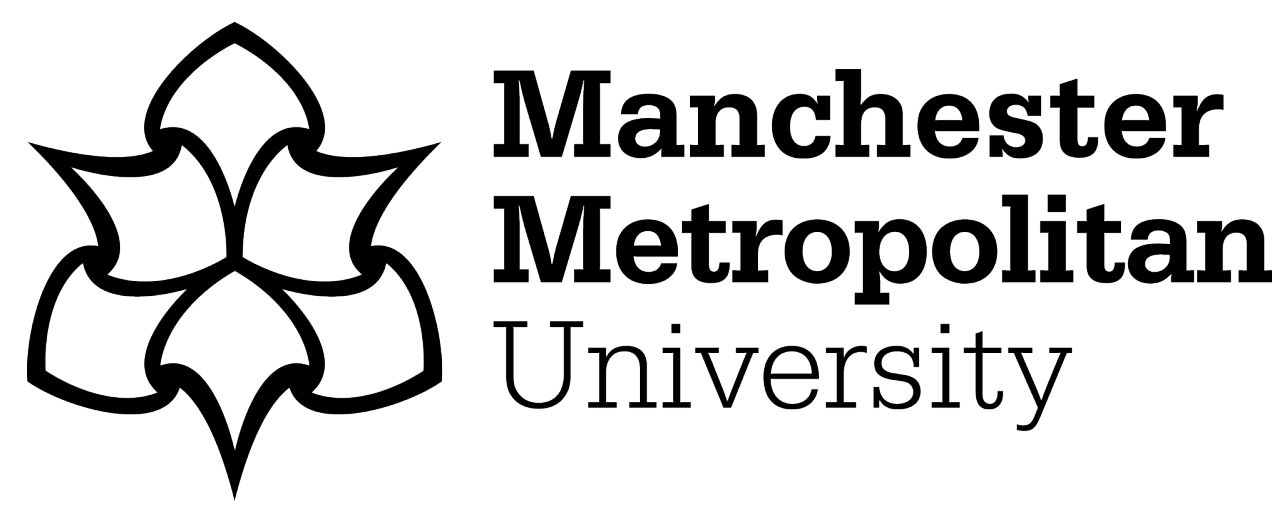

Bond, AJ, Widdop, P ORCID logoORCID: https://orcid.org/0000-0003-03347053 and Chadwick, S (2018) Football's emerging market trade network: ego network approach to world systems theory. Managing Sport and Leisure, 23 (1-2). pp. 70-91. ISSN 2375-0472

Downloaded from: https://e-space.mmu.ac.uk/624971/

Version: Accepted Version

Publisher: Taylor \& Francis

DOI: https://doi.org/10.1080/23750472.2018.1481765

Please cite the published version 


\title{
Football's emerging market trade network: ego network approach to world systems theory
}

\author{
Alexander John Bond ${ }^{\mathrm{a}}$, Paul Widdop ${ }^{\mathrm{a}}$ and Simon Chadwick ${ }^{\mathrm{b}}$ \\ ${ }^{\mathrm{a} S}$ Sport Business Group, Leeds Beckett University, Leeds, UK; ${ }^{\mathrm{b}}$ Centre for Sport Business, University of Salford, Salford, UK
}

\begin{abstract}
The football transfer market is a billion-pound industry, traditionally dominated by the European market. This has been challenged by the rise of relatively new markets emerging from China, Brazil, Turkey and Russia. Important countries within the market, they also challenge the traditional status order. While classical international trade theorists suggest that capital or resource advantage predicts trade, economic sociologists argue that a world-systems perspective economic relationships are a core component. Therefore, we analyse the football trade network of these emerging markets to understand the structure, specifically in relation to the world-systems perspective. Using social network analysis, we identify the network is structured analogously to a world-systems perspective with a core of European countries, a semi-periphery of developing countries and a periphery containing countries where football is less developed. Furthermore, Turkey and Brazil occupy structural holes acting as brokers between the core, semi-periphery and periphery positions which can be advantageous.
\end{abstract}

\section{ARTICLE HISTORY}

Received 31 January 2018

Accepted 14 May 2018

\section{KEYWORDS}

World-systems;

embeddedness; economic networks; football market; football industry; economic sociology

\section{Introduction}

Within a world-systems perspective of trade, there is a distinct division of labour that manifests itself structurally through three layers, a core, semi-periphery and periphery. The core representing the elite economies (mostly western), the periphery representing predominantly less developed, or global south countries (Therien, 1999), with weak economies and governments, and the semi-periphery compromising of more developed, often industrial economies (Wallerstein, 2004). Indeed, a world-systems approach to economic transactions amongst countries has generated considerable interest from a variety of different commodity imports and exports (cf. ChaseDunn \& Grimes, 1995; Massey et al., 1993;
Nemeth \& Smith, 1985; Sarajlić, Malod-Dognin, Yaveroğlu, \& Pržulj, 2016; Zhang, 2017), yet the global sports market has had limited attention. This is ironic, given that the global sports market has been valued anywhere between $\$ 700$ billion and \$1.5 trillion (Kearney, 2011; Plunkett Research, 2017). Furthermore, whilst a world-systems theory has well established roots in the more sociologically led branch of economics, the role of network theory (social network analysis) has been given limited attention, with the exception of the exemplary work by Snyder and Kick (1979), and Kick, McKinney, McDonald, and Jorgenson (2011), even though it is a central theory in the sub-disciplines of economic sociology and economic geography. Therefore, in this paper we add to the literature by exploring trade in global football through a 
world-systems perspective, adopting a social network perspective to address how this trade is structured, with a specific emphasis on footballs emerging global markets, of China, Brazil, Turkey and Russia, which we believe are challenging the assumed elite.

The "association football" (herein football) market remains the largest sports market globally, estimated to account for $43 \%$ of the market share (Kearney, 2011). Expenditure on players represents the largest investment for firms (clubs) in the market, with an estimated $\$ 4.79$ billion spent in 2016 (FIFA, 2017a), and \$6 billion in 2017 (FIFA, 2017b). There is considerable value in the global transfer market, which cuts across national territories, with 15,290 trades (commonly referred to as a transfer) taking place between January and October 2017 (FIFA, 2017b; up from 14,591 in 2016), and whilst Europe is involved in a large proportion of these trades, certain global emerging markets are increasingly improving their position. Indeed, one such country who is China, who were aggressive in their spending, becoming the leading nation in player expenditure for the $16 / 17$ winter transfer window, investing $£ 300 \mathrm{~m}, £ 100 \mathrm{~m}$ more than England (Deloitte, 2017). Given the significance of football to nations, culturally and economically, and the substantial flows of trade globally, football warrants academic attention, in similar ways to the trade of precious metals, food, minerals and other consumer products.

In its simplest form football's "transfer market" represents trade of services where there are sets of buyers and sellers who exchange money to acquire football players. As Morrow (1996) notes, the player is not the asset, the service they provide is and is thus the traded commodity. Accordingly, in this paper, we treat players and the service they provide (termed football or talent resource) as an asset being traded on the market. Indeed, this "market" becomes more complex when including the loan system (a form of cross-subsidisation whereby one club temporarily provides talent resources to other clubs for a fixed period-of-time) and free agents (players not contracted to a club and therefore are not traded). However, in this paper, we restrict the analysis to considering only the flow of football services from the selling to buying club aggregated to nations, or essentially the flow of money between countries trading in the footballing commodity of players.

The buying and selling of footballing resource, either domestically or internationally, create a trade network at an individual club level and, importantly for this paper, an aggregated country level network. Unfortunately, very little attention has been paid to this aggregated networked model. Yet, over the last decade, economic network research has grown exponentially - mainly through the contributions of Arthur (1999), Wilhite (2001), Jackson (2010, 2014), Vega-Redondo (2007) and Goyal (2012) (for an introduction on economic networks see Knoke, 2012). However, network analysis is not commonplace within economics. This probably reflects the mainstream neo-classical economic foundations upon which international trade theories were developed. Under this tradition, various assumptions are made, including: how actors, whether individuals, firms or countries, make rational choices to maximise utility/profits within a budget constraint; perfect competition within a market allows actors to have access to complete information to make a utility/profit maximising decisions that satisfy their self-interest (Knoke, 2012; Simon, 1955). In doing so they often reject the cultural, religious, political and social relational implications economic sociologist's Mark Granovetter (1985), Nan Lin (2002) and others suggest are embedded in economic activity. As such, trade from an economic sociological perspective has focused on Immanuel Wallerstien's (1974a, 1974b) world-systems postulation, that trade relations with underdeveloped resource-rich countries are exploited by the rich capital nations; creating a tripartite trade network of the periphery; semi-periphery 
and core. It is this approach that is of interest in this paper.

With the exception of Liu, Liu, Lu, Wang, and Wang (2016), football's international trade network remains under-researched. Indeed, whilst Liu et al. (2016) provide insightful work to build upon, Wallerstien's world-systems approach offers a stronger theoretical position for which to explore the football trade system. Therefore, this paper firstly aims to provide an exploratory analysis of the football's emerging markets trade network (FEMTN) - made up of China, Russia, Brazil and Turkey, and secondly aims to identify if the world-systems postulation holds true within the FEMTN, by answering the following research questions;

(i) Which countries occupy powerful or influential positions with the FEMTN?

(ii) Does the FEMTN conform to the worldsystems perspective?

\section{Trade and networks}

International trade has long been a central concern for disciplines of the social sciences, especially within economics, sociology, politics and international relations. In its simplest form, it represents economic exchange across country borders and until discipline-defining work by Adam Smith ([1776] 1937 with Wealth of Nations, it was considered mercantilist, advocating nationalist protectionism. Since this mercantilist era of the 16th, 17th and mid-18th centuries, international trade theories have transformed from Adam Smith's absolute advantage theory of free trade through division of labour, to David Ricardo's ([1817] 1951) comparative advantage of cost differentiation, later refined and publicised by noteworthy authors, namely, Mill, J.S. Mill, Marshall, Torrens, Taussig, Haberler and Samuelson (cf. Aldrich, 2004; Chipman, 1965a, 1965b; Ruffin, 2005; Thweatt, 1976). However, Ricardian theories of international trade did not consider how differentiation occurred, leading Heckscher (1919) and Ohlin (1933) to extend the Ricardian theory to account for "factor endowments" with the Heckscher-Ohlin theorem (Ito, Rotunno, \& Vézina, 2017; Jones, 1956). These theory states that capital rich counties export capital-intensive goods and labour rich countries export labour-intensive goods, with both importing the alternate. Unfortunately, the assumptions these theories are founded upon, such as perfect competition and ubiquitous technology, do not hold true. This is especially the case at this point in the twentyfirst Century, where markets have monopolies and oligopolies, and countries have different technological advances.

To readjust this imbalance, several trade theorists have attempted to account for differentiating technological advances; Posner's (1961) Imitation (Technology) Gap theory, and imperfect market competition (Brander \& Krugman, 1983; Krugman, 1979), to name two. However, much like previous models of international trade, empirical models often fall short of theoretical and mathematical specifications. One argument is that they fail to account for the relational elements (and their associated costs) inherent in trade, something Kranton and Minehart (2001) explored in their theory of the Buyer-Seller network, but there remains a serious underdevelopment and limitation in the literature accounting for the relational elements of economic activity. Indeed, within (neo)-classical economics, the relations between actors have been treated as a "frictional drag" impeding competition within markets (Granovetter, 1985, p. 484). Which is surprising since Nobel prize-winner Ronald Coase (1960) stated through his theory of transaction cost economics that it is the cost of forming and maintaining beneficial relationships that dominates decision-making.

That said, within the "complex systems" literature, the world economy often takes centre stage cutting across multiple disciplines; such as physics, computer science, economics, finance and international business (Almog, 
Squartini, \& Garlaschelli, 2017; Bargigli \& Gallegati, 2011; Baskaran, Blöchl, Brück, \& Theis, 2011; Garlaschelli \& Loffredo, 2004, 2005, 2007; Fagiolo, Reyes, \& Schiavo, 2009, 2010; Fronczak \& Fronczak, 2012; Kali \& Reyes, 2007, 2010; Maratea, Petrosino, \& Manzo, 2016; Serrano \& Boguná, 2003; Squartini, Fagiolo,\& Garlaschelli,2011a,2011b). Whilst these disciplines increase our understanding of economic networks in practice, they often omit the position and role within networks which economic sociologists are concerned with (Granovetter, 2005; Knoke, 2012; Lin, 2002).

World system theorists and, similarly, dependency theorists, argue that position within the global trade network is fundamental to economic development, given relationships and power dynamics inherent in such systems (Bornschier \& Chase-Dunn, 1985; Frank, 1966). Wallerstein (1974a, 1974b) extended the bipartite Marxist-infused dependency theory of the core developed rich capital nations exploiting the resources of poor underdeveloped peripheral counties (Frank, 1966), coining the Worldsystems theory (or the world-systems perspective). Wallerstein essentially stratified economic development into three components or trading blocks; a core, a semi-periphery and a periphery (Wallerstein, 1974a, 1974b). This was empirically supported by Snyder and Kick (1979), who successfully block modelled 118 countries into a core (Western Europe, North America, Japan, Australia and South Africa), semi-periphery (Soviet Union, Eastern Europe, Cuba and Middle Eastern countries) and a periphery (Africa, South America and Asian developing countries), whilst also accounting for noneconomic relations impacting trade, such as military, treaty membership and diplomatic ties. However, Kick et al. (2011) returning to this 1979 study, following the same economic and noneconomic linkages and logic, found similar results with three core trading blocks, the centre core of US, UK, France, Germany, Italy and Netherlands along with a Western Europe block (which also included Brazil,
Turkey and Israel) and Asian block of China, India and Japan along with Australia, Canada and South Africa. With other blocks resembling consistent (semi) periphery positions (South America, Africa, former Soviet Union countries).

Whilst these studies offer an exemplary foundation for the exploration of the network structure in global trading between nations, we can further draw on academic literature within economic sociology to further support these studies. In particular, for this paper, we are interested in structural and relational embeddedness, as proposed by Granovetter $(1985,2017)$. For Granovetter, all economic behaviour is rooted and embedded in social relations, as such decisions, be it buying a football player or the trading of diamonds, economic behaviour is structured by social interactions and relationships. Indeed, Durkheim's thoughts within his epitome Division of Labour, shares sensibilities to this idea, noting that,

even where society rests wholly upon the division of labour, it does not resolve itself into a myriad of atoms juxtaposed together, between which only external and transitory contact can be established. The members are linked by ties that extend well beyond the very brief moment when the act of exchange is being accomplished. (Durkheim, 1984; Granovetter, 2017)

Embeddedness works on the premise that economic actions (players, clubs, countries and federations) are impacted by: connections to others, their position they occupy, and also by the structure of the overall network. This idea of embeddedness is contrary to the neo-classical frameworks dominant in economics, which are based on utility maximisation and rational atomised actors, placing great emphasis on how position and structure constrain behaviour. The idea of position is a central argument in this paper. Ronald Burt (1992), in thinking about a position in a network - especially in relation to the advantage that it can create, coined the term "structural hole". For Burt, individual or organisations with ties into multiple networks 
that are otherwise unconnected enjoy a competitive and strategic advantage. In such a situation, the said actor spans what Burt calls a structural hole, thus controlling what is flowing through the network. Being in such a strategic potion allows them to exploit the structural hole in the networks they join (Burt, 1992). Individuals are effectively brokers and can thus leverage and trade off what is flowing, be it money or information.

Football's trade network has been seldom researched in terms of world-systems or, for that matter, through the principles of embeddedness. Hence, we address this by placing structure through networks at the centre of our methodological approach, bringing these two concepts together. Furthermore, as an extra nuance, we explore these network structures focusing on key emerging countries in football trade, id est those countries which are growing in statue as a force within the football market, these include; China, Brazil, Turkey and Russia. The rationale for this is two-fold. First, not only do these countries feature as core blocks within Kick et al. (2011) study, but they are all ranked as highly significant internationally trading countries within their respective football confederations (FIFA, 2017a, 2017b, 2017c). Taking an exploratory approach, this paper will identify if the football trade involving the emerging markets can be stratified into different positions, matching onto results reported in the previous literature on worldsystems approach. In addition, network analysis will provide fundamental network metrics which will allow us to position football research within the wider literature on trade. A key prerequest for structural analysis of this kind is noted by Borgatti and Halgin (2011), identifying that prior to analysing a network, the boundary must be defined, and, following the nominalist view (Knoke \& Yang, 2008), in this instance the boundary of football's emerging market trade network (FEMTN) comprises of international football trade concerning the aforementioned countries. Thus, we can treat this as a whole network for these countries, though it is acknowledged this is an ego network of these four counties from the larger global football trade network.

\section{Method and data}

To investigate the FEMTN, we utilise Network Analysis - often referred to as Social Network Analysis (SNA). The essence of SNA can be traced back to Georg Simmel ([1922] 1955]) in his The Web of Group Affiliations, however, it was social psychologist Jacob Moreno (1932, 1934) who first developed the sociogram what is now the classical visual representation of networks. Yet, it was Cartwright and Harary (1977) who gave the sociogram a solid grounding in Graph Theory - which is now the norm in today's SNA. A network or graph describes a set of elements, termed nodes, vertices or actors, that are connected through interactions and relationships, termed edges or ties (VegaRedondo, 2007). Following Wasserman and Faust (2009) and De Benedictis, Nenci, Santoni, Tajoli, and Vicarelli (2014) a graph is noted as $G=(V, L)$ compromised of a set of nodes $V$ (or vertices or actors) and a set of edges $L$ (or ties or links), or $L \in V \times V$. In this paper we identify $n$ $=69$ different countries involved in the FEMTN, $V=(1,2,3, \ldots, 69)$ with 203 football transfers (trade connections) between them, thus $L=(1,2,3, \ldots, 203)$. By knowing who trades with whom we are able to create a network visualisation of the structure of these trading patterns.

Moreover, as the edges follow the direction of trade (otherwise referred to as arcs), from exporting country $i$ to importing country $j$, then, $L_{i j} \in\{0,1\}$, with $L_{i j}=1$ showing a trade relationship and $L_{i j}=0$ where a trade relationship does not exist. This can be represented in an asymmetric adjacency matrix, $\boldsymbol{A}=n \times n$ ( $n$ representing the number of nodes in the network). Hence, $L_{i j}$ in the adjacency matrix $\boldsymbol{A}$ is not equal to $L_{j i}$ or, the edge from country $i$ to $j$, does not necessarily imply an edge from 
country $j$ to $i$ exists nor does it mean the weight is equal if one does.

If we then account for the weight of the trade relationship between $i$ and $j$, and other relevant information on the nodes and arcs then the network can be noted as $N=(G(V, L), W, P)$. With $W$ representing edge characteristics, such as the value of the relationship and $P$ includes node specific information, in this instance the country label following ISO 3 country codes. In addition to the exogenous information for both $W$ and $P$, endogenous information can also be included, mostly those associated with the topological properties of the node (country) within the trade network structure. It is the topological properties of the FEMTN that is of interest to this paper and the following presents such. Following previous work by Liu et al. (2016), all football trade data for the $16 / 17$ season was compiled from Opta Sports' transfer database soccerway.com. To validate the data, all observations were corroborated with transfermarkt.com - another industry provider of football transfer data, and news outlets such as BBC sport, ESPN, The Telegraph and The Guardian. Network properties were calculated and visualised using the network software UCINET (Borgatti, Everett, \& Freeman, 2002) and Figure 1 was generated using Gephi software (Bastian, Heymann, \& Jacomy, 2009). The circles represent countries and the lines that join these countries are arcs or edges, which represent a transaction. Furthermore, the edge/arc is also weighted here to account for the volume of transactions between two nodes, whilst the size of the nodes represents how central they are, larger being more central. In the following section, we use this sociogram (Figure 1) as a visual guide to exploring the network through various graph metrics and network analysis.

\section{Football's emerging market trade network properties}

The most common and simplest endogenous network properties are those associated with centrality, which is a measure of how central a country is within the trade network. Jackson (2010) notes that there are four main measures of how central a node or actor maybe, these include; degree centrality $\left(C_{D}\right)$ which measures a node's connectedness to other nodes; closeness centrality $\left(C_{C}\right)$ a measure indicating how easy a node can be reached by other nodes; betweenness centrality $\left(C_{B}\right)$ a measure of the nodes importance in terms of connecting other nodes; we term the final type "centrality power" which incorporates two related measures, eigenvector centrality, $\left(C_{E}\right)$, and Bonacich centrality $\left(C_{P}\right)$, representing the importance, centrality and influential a node's neighbours are. Fundamentally, centrality measures can identify those actors who hold power and influence within networks, so these measures are well placed to provide insight to the structure of the trade network and the position of certain countries within it. Furthermore, it allows us, somewhat superficially, to explore ideas of embeddedness (Granovetter, 1985) and positions of advantage such as structural holes and brokerage (Burt, 1992). That is, these measures will enable us to explore positions of countries within our bounded network, allowing us to interpret the position in relation to the theoretical frameworks introduced earlier in the paper. In the following section, we articulate our use of these centrality measures as they are central to our arguments, we start with the simplest measure degree centrality. Table 1 includes the results of the measures.

\section{Degree centrality}

Degree centrality is the simplest property of network position for a node or, in our case, trading country. Essentially, this metric measures centrality based on the number of connections a node has. Formally, the normalised measure of $C_{D}$ can be written as;

$$
C_{D}=\frac{\sum_{j \neq i}^{N} \mathcal{L}_{i j}}{(N-1)} .
$$




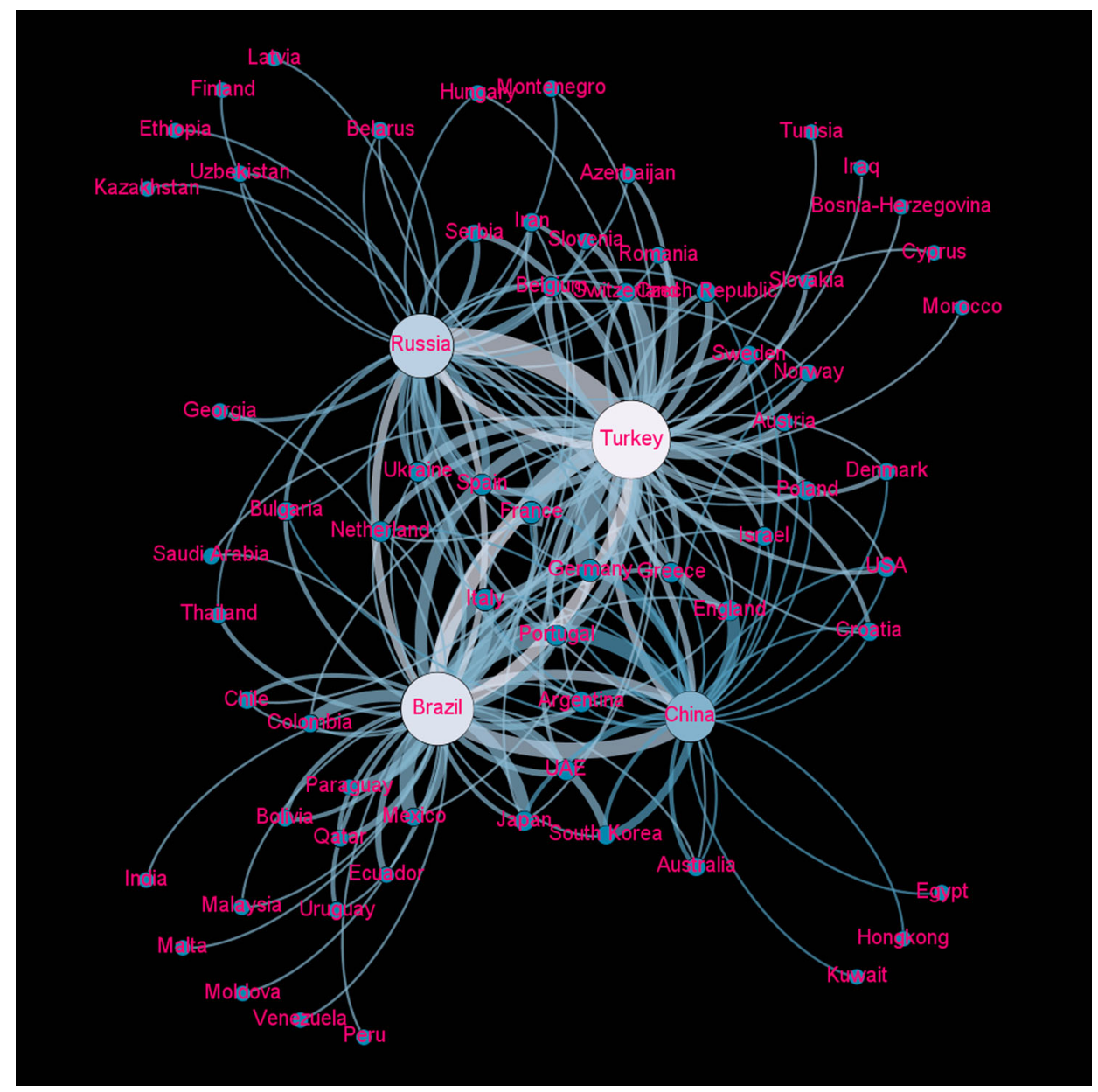

Figure 1. Trade map of FEMTN.

Normalising this measure is often used for comparisons of differing network size or time, and although we do not use it for those purposes here, it gives a better understanding of node degree centrality in relation to the whole FEMTN network; hence $N-1$ ( $N$ representing the total number of nodes in $G$ ). Moreover, within a directed network, such as the FEMTN, there are two measures of degree centrality; in-degree - based on the number of arcs flowing into a node, and out-degree - articulating the number of arcs exiting a node. Therefore, in-degree, noted as $\sum_{j \neq i}^{N} \mathcal{L}_{j i}$, for the FEMTN represents the total number of football (player) imports (or purchases) of country $i$, and out-degree, noted as $\sum_{j \neq i}^{N} \mathcal{L}_{i j}$, shows the total number of football (player) exports (or sales) of country $i$. The formal notations are as follows:

$$
\begin{gathered}
C_{D_{\text {in }}}^{i}=\frac{\sum_{j \neq i}^{N} \mathcal{L}_{j i}}{(N-1)} \\
C_{D_{\text {out }}}^{i}=\frac{\sum_{j \neq i}^{N} \mathcal{L}_{i j}}{(N-1)}
\end{gathered}
$$

Not accounting for the weight of the ties, Table 1 presents these results. Although the emerging market countries will demonstrate 
Table 1. Topological properties of the FEMTN.

\begin{tabular}{|c|c|c|c|c|c|c|c|c|c|c|c|c|c|c|c|c|c|}
\hline \multirow[b]{2}{*}{ i } & \multicolumn{2}{|c|}{ Degree } & \multicolumn{2}{|c|}{ Closeness } & \multirow{2}{*}{$\begin{array}{l}\text { Betweenness } \\
\qquad C_{B}^{i} \\
\end{array}$} & \multicolumn{3}{|c|}{ Power } & \multicolumn{3}{|c|}{ Structural holes } & \multirow{2}{*}{$\begin{array}{c}\begin{array}{c}\text { World } \\
\text { systems }\end{array} \\
\text { K-Core }\end{array}$} & \multicolumn{5}{|c|}{ Brokerage } \\
\hline & $C_{D_{\text {out }}}^{i}$ & $C_{D_{\text {in }}}^{i}$ & $C_{C_{\text {out }}}^{i}$ & $C_{C_{\text {in }}}^{i}$ & & $C_{E}^{i}$ & $C_{P_{\text {in }}}^{i}$ & $C_{P_{\text {out }}}^{i}$ & $\begin{array}{l}\text { Effect } \\
\text { Size }\end{array}$ & Efficiency & Constraint & & Coordinator & Gatekeeper & Represent & Consultant & Liaison \\
\hline ARG & 0.059 & 0.029 & 0.36 & 0.389 & 0 & 0.152 & -0.309 & 0.284 & 2.427 & 0.607 & 0.621 & 4 & 0 & 0 & 0 & 0 & 0 \\
\hline AUS & 0.015 & 0.044 & 0.298 & 0.422 & 0 & 0.003 & 0.015 & 0 & 2.549 & 0.85 & 0.941 & 3 & 0 & 0 & 0 & 0 & 0 \\
\hline AUT & 0.044 & 0 & 0.345 & 0.2 & 0 & 0.064 & 0 & 0.016 & 1.912 & 0.637 & 0.789 & 3 & 0 & 0 & 0 & 0 & 0 \\
\hline AZE & 0.029 & 0 & 0.338 & 0.2 & 0 & 0.005 & 0 & 0.041 & 1.562 & 0.781 & 0.889 & 2 & 0 & 0 & 0 & 0 & 0 \\
\hline BEL & 0.044 & 0.029 & 0.356 & 0.402 & 0 & 0.015 & 0.059 & 0.03 & 2.08 & 0.693 & 0.494 & 3 & 0 & 0 & 0 & 0 & 0 \\
\hline BGR & 0.015 & 0.044 & 0.309 & 0.422 & 0 & 0.004 & 0.006 & 0.022 & 2.153 & 0.718 & 0.626 & 3 & 0 & 0 & 0 & 0 & 0 \\
\hline BIH & 0.015 & 0 & 0.319 & 0.2 & 0 & 0.001 & 0 & 0.01 & 1 & 1 & 1 & 1 & 0 & 0 & 0 & 0 & 0 \\
\hline BLR & 0.015 & 0.029 & 0.309 & 0.402 & 0 & 0.002 & 0.005 & 0.012 & 1.223 & 0.612 & 0.667 & 2 & 0 & 0 & 0 & 0 & 0 \\
\hline $\mathrm{BOL}$ & 0.015 & 0.015 & 0.325 & 0.36 & 0 & 0.001 & 0.006 & 0 & 1 & 1 & 1 & 1 & 0 & 0 & 0 & 0 & 0 \\
\hline BRA & 0.471 & 0.412 & 0.422 & 0.527 & 27.838 & 0.241 & 0.125 & 0.16 & 36.617 & 0.939 & 0.207 & 4 & 79 & 221 & 179 & 0 & 331 \\
\hline CHE & 0.029 & 0.029 & 0.333 & 0.402 & 0 & 0.01 & 0.012 & 0.089 & 1.489 & 0.745 & 0.751 & 2 & 0 & 0 & 0 & 0 & 0 \\
\hline $\mathrm{CHL}$ & 0.015 & 0.029 & 0.325 & 0.412 & 0 & 0.004 & 0.016 & 0.002 & 1.483 & 0.742 & 0.705 & 2 & 0 & 0 & 0 & 0 & 0 \\
\hline $\mathrm{CHN}$ & 0.191 & 0.353 & 0.378 & 0.486 & 9.191 & 0.614 & 0.145 & 0.161 & 26.42 & 0.911 & 0.265 & 4 & 32 & 63 & 71 & 0 & 87 \\
\hline $\mathrm{COL}$ & 0.029 & 0.015 & 0.343 & 0.36 & 0 & 0.01 & 0.004 & 0.01 & 1.458 & 0.729 & 0.915 & 2 & 0 & 0 & 0 & 0 & 0 \\
\hline CYP & 0 & 0.015 & 0.2 & 0.391 & 0 & 0.001 & 0.005 & 0 & 1 & 1 & 1 & 1 & 0 & 0 & 0 & 0 & 0 \\
\hline CZE & 0.044 & 0.029 & 0.34 & 0.402 & 0.02 & 0.038 & 0.017 & 0.002 & 2.093 & 0.698 & 0.57 & 3 & 0 & 0 & 0 & 1 & 0 \\
\hline DEU & 0.059 & 0.044 & 0.36 & 0.433 & 0.02 & 0.141 & 0.181 & 0.197 & 2.82 & 0.705 & 0.397 & 4 & 1 & 0 & 0 & 0 & 0 \\
\hline DNK & 0.029 & 0.015 & 0.329 & 0.384 & 0.02 & 0.018 & 0.007 & -0.007 & 1.965 & 0.983 & 0.601 & 2 & 0 & 0 & 0 & 1 & 0 \\
\hline ECU & 0.015 & 0 & 0.33 & 0.2 & 0 & 0.007 & 0 & 0.004 & 1 & 1 & 1 & 1 & 0 & 0 & 0 & 0 & 0 \\
\hline EGY & 0.015 & 0 & 0.302 & 0.2 & 0 & 0.027 & 0 & -0.035 & 1 & 1 & 1 & 1 & 0 & 0 & 0 & 0 & 0 \\
\hline ESP & 0.044 & 0.044 & 0.34 & 0.433 & 0.02 & 0.163 & 0.434 & 0.326 & 2.712 & 0.678 & 0.416 & 4 & 1 & 0 & 0 & 0 & 0 \\
\hline ETH & 0.015 & 0 & 0.313 & 0.2 & 0 & 0 & 0 & 0 & 1 & 1 & 1 & 1 & 0 & 0 & 0 & 0 & 0 \\
\hline FIN & 0 & 0.015 & 0.2 & 0.37 & 0 & 0.001 & 0 & 0 & 1 & 1 & 1 & 1 & 0 & 0 & 0 & 0 & 0 \\
\hline FRA & 0.044 & 0.059 & 0.356 & 0.444 & 0 & 0.073 & 0.045 & 0.639 & 2.866 & 0.717 & 0.622 & 4 & 0 & 0 & 0 & 0 & 0 \\
\hline GBR & 0.044 & 0.044 & 0.349 & 0.433 & 0.02 & 0.454 & 0.191 & -0.252 & 2.653 & 0.663 & 0.609 & 4 & 1 & 0 & 0 & 0 & 0 \\
\hline GEO & 0.015 & 0.015 & 0.327 & 0.366 & 0 & 0.002 & 0 & 0 & 1.723 & 0.862 & 0.587 & 2 & 0 & 0 & 0 & 0 & 0 \\
\hline GRC & 0.029 & 0.044 & 0.329 & 0.433 & 0.02 & 0.066 & 0.1 & 0.017 & 2.757 & 0.689 & 0.483 & 4 & 1 & 0 & 0 & 0 & 0 \\
\hline HKG & 0 & 0.015 & 0.2 & 0.345 & 0 & 0 & -0.003 & 0 & 1 & 1 & 1 & 1 & 0 & 0 & 0 & 0 & 0 \\
\hline HRV & 0.029 & 0.029 & 0.329 & 0.395 & 0.02 & 0.009 & 0.015 & 0.033 & 1.98 & 0.99 & 0.653 & 2 & 0 & 0 & 0 & 1 & 0 \\
\hline HUN & 0.015 & 0.015 & 0.316 & 0.366 & 0 & 0.003 & 0 & 0.006 & 1.223 & 0.612 & 0.667 & 2 & 0 & 0 & 0 & 0 & 0 \\
\hline IND & 0.015 & 0 & 0.33 & 0.2 & 0 & 0.001 & 0 & 0.001 & 1 & 1 & 1 & 1 & 0 & 0 & 0 & 0 & 0 \\
\hline IRN & 0.044 & 0.015 & 0.356 & 0.384 & 0 & 0.005 & 0.012 & 0.045 & 2.095 & 0.698 & 0.623 & 3 & 0 & 0 & 0 & 0 & 0 \\
\hline IRQ & 0.015 & 0 & 0.319 & 0.2 & 0 & 0 & 0 & 0.001 & 1 & 1 & 1 & 1 & 0 & 0 & 0 & 0 & 0 \\
\hline ISR & 0.029 & 0.029 & 0.329 & 0.412 & 0.02 & 0.037 & 0.083 & 0.019 & 2.535 & 0.845 & 0.495 & 3 & 0 & 0 & 0 & 1 & 0 \\
\hline ITA & 0.059 & 0.044 & 0.36 & 0.422 & 0.02 & 0.15 & 0.598 & 0.346 & 2.877 & 0.719 & 0.455 & 4 & 1 & 0 & 0 & 0 & 0 \\
\hline JPN & 0.044 & 0.029 & 0.349 & 0.412 & 0.02 & 0.013 & 0.086 & 0.046 & 2.424 & 0.808 & 0.558 & 3 & 0 & 0 & 0 & 1 & 0 \\
\hline KAZ & 0.015 & 0 & 0.313 & 0.2 & 0 & 0.002 & 0 & 0.018 & 1 & 1 & 1 & 1 & 0 & 0 & 0 & 0 & 0 \\
\hline
\end{tabular}


Table 1. Continued.

\begin{tabular}{|c|c|c|c|c|c|c|c|c|c|c|c|c|c|c|c|c|c|}
\hline \multirow[b]{2}{*}{$i$} & \multicolumn{2}{|c|}{ Degree } & \multicolumn{2}{|c|}{ Closeness } & \multirow{2}{*}{$\begin{array}{l}\text { Betweenness } \\
\qquad C_{B}^{i} \\
\end{array}$} & \multicolumn{3}{|c|}{ Power } & \multicolumn{3}{|c|}{ Structural holes } & \multirow{2}{*}{$\begin{array}{c}\begin{array}{c}\text { World } \\
\text { systems }\end{array} \\
\text { K-Core }\end{array}$} & \multicolumn{5}{|c|}{ Brokerage } \\
\hline & $C_{D_{\text {out }}}^{i}$ & $C_{D_{\text {in }}}^{i}$ & $C_{C_{\text {out }}}^{i}$ & $C_{C_{\text {in }}}^{i}$ & & $C_{E}^{i}$ & $C_{P_{\text {in }}}^{i}$ & $C_{P_{\text {out }}}^{i}$ & $\begin{array}{l}\text { Effect } \\
\text { Size }\end{array}$ & Efficiency & Constraint & & Coordinator & Gatekeeper & Represent & Consultant & Liaison \\
\hline KOR & 0.029 & 0.029 & 0.333 & 0.389 & 0 & 0.008 & -0.231 & -0.006 & 1.659 & 0.83 & 0.566 & 2 & 0 & 0 & 0 & 0 & 0 \\
\hline KWT & 0.015 & 0 & 0.302 & 0.2 & 0 & 0 & 0 & 0 & 1 & 1 & 1 & 1 & 0 & 0 & 0 & 0 & 0 \\
\hline LVA & 0.015 & 0 & 0.313 & 0.2 & 0 & 0.002 & 0 & 0.018 & 1 & 1 & 1 & 1 & 0 & 0 & 0 & 0 & 0 \\
\hline MAR & 0.015 & 0 & 0.319 & 0.2 & 0 & 0 & 0 & 0.004 & 1 & 1 & 1 & 1 & 0 & 0 & 0 & 0 & 0 \\
\hline MDA & 0 & 0.015 & 0.2 & 0.366 & 0 & 0.001 & 0.003 & 0 & 1 & 1 & 1 & 1 & 0 & 0 & 0 & 0 & 0 \\
\hline MEX & 0.015 & 0.029 & 0.325 & 0.412 & 0 & 0.018 & 0.067 & 0.009 & 1.46 & 0.73 & 0.892 & 2 & 0 & 0 & 0 & 0 & 0 \\
\hline MLT & 0 & 0.015 & 0.2 & 0.366 & 0 & 0 & 0 & 0 & 1 & 1 & 1 & 1 & 0 & 0 & 0 & 0 & 0 \\
\hline MNE & 0.029 & 0 & 0.338 & 0.2 & 0 & 0 & 0 & 0.002 & 1.607 & 0.803 & 0.996 & 2 & 0 & 0 & 0 & 0 & 0 \\
\hline MYS & 0.015 & 0.015 & 0.325 & 0.36 & 0 & 0 & 0.002 & 0 & 1 & 1 & 1 & 1 & 0 & 0 & 0 & 0 & 0 \\
\hline NLD & 0.059 & 0.029 & 0.36 & 0.412 & 0.02 & 0.023 & 0.001 & -0.007 & 2.611 & 0.653 & 0.666 & 4 & 1 & 0 & 0 & 0 & 0 \\
\hline NOR & 0.015 & 0.029 & 0.316 & 0.393 & 0 & 0.004 & -0.003 & 0.018 & 2.194 & 0.731 & 0.689 & 3 & 0 & 0 & 0 & 0 & 0 \\
\hline PER & 0.015 & 0 & 0.33 & 0.2 & 0 & 0.001 & 0 & 0 & 1 & 1 & 1 & 1 & 0 & 0 & 0 & 0 & 0 \\
\hline POL & 0.044 & 0.029 & 0.34 & 0.412 & 0.02 & 0.006 & 0.018 & 0.013 & 2.937 & 0.734 & 0.586 & 4 & 1 & 0 & 0 & 0 & 0 \\
\hline PRT & 0.059 & 0.029 & 0.36 & 0.412 & 0.02 & 0.082 & 0.347 & 0.101 & 2.992 & 0.748 & 0.511 & 4 & 1 & 0 & 0 & 0 & 0 \\
\hline PRY & 0 & 0.015 & 0.2 & 0.366 & 0 & 0.005 & 0.032 & 0 & 1 & 1 & 1 & 1 & 0 & 0 & 0 & 0 & 0 \\
\hline QAT & 0.015 & 0.015 & 0.325 & 0.36 & 0 & 0.006 & 0.022 & 0.003 & 1 & 1 & 1 & 1 & 0 & 0 & 0 & 0 & 0 \\
\hline ROU & 0.029 & 0 & 0.338 & 0.2 & 0 & 0.012 & 0 & 0.112 & 1.464 & 0.732 & 0.715 & 2 & 0 & 0 & 0 & 0 & 0 \\
\hline RUS & 0.309 & 0.441 & 0.395 & 0.535 & 19.377 & 0.42 & 0.125 & 0.158 & 30.254 & 0.818 & 0.37 & 4 & 45 & 134 & 133 & 0 & 239 \\
\hline SAU & 0.029 & 0 & 0.349 & 0.2 & 0 & 0.003 & 0 & 0.016 & 1.546 & 0.773 & 0.582 & 2 & 0 & 0 & 0 & 0 & 0 \\
\hline SRB & 0.029 & 0.015 & 0.333 & 0.364 & 0 & 0.015 & -0.001 & 0.141 & 1.218 & 0.609 & 0.672 & 2 & 0 & 0 & 0 & 0 & 0 \\
\hline SVK & 0.015 & 0 & 0.319 & 0.2 & 0 & 0.002 & 0 & 0.021 & 1 & 1 & 1 & 1 & 0 & 0 & 0 & 0 & 0 \\
\hline SVN & 0.029 & 0 & 0.338 & 0.2 & 0 & 0.004 & 0 & 0.036 & 1.44 & 0.72 & 0.686 & 2 & 0 & 0 & 0 & 0 & 0 \\
\hline SWE & 0.044 & 0.015 & 0.34 & 0.384 & 0.02 & 0.024 & 0.052 & 0.028 & 2.289 & 0.763 & 0.534 & 3 & 0 & 0 & 0 & 1 & 0 \\
\hline THA & 0.015 & 0.015 & 0.311 & 0.362 & 0 & 0.005 & 0.026 & 0.007 & 1.773 & 0.887 & 0.858 & 2 & 0 & 0 & 0 & 0 & 0 \\
\hline TUN & 0.015 & 0 & 0.319 & 0.2 & 0 & 0.001 & 0 & 0.006 & 1 & 1 & 1 & 1 & 0 & 0 & 0 & 0 & 0 \\
\hline TUR & 0.382 & 0.588 & 0.405 & 0.581 & 25.525 & 0.241 & 0.124 & 0.159 & 41.797 & 0.95 & 0.216 & 4 & 97 & 278 & 184 & 0 & 394 \\
\hline UAE & 0.044 & 0.029 & 0.349 & 0.412 & 0.02 & 0.066 & 0.08 & -0.008 & 2.382 & 0.794 & 0.451 & 3 & 0 & 0 & 0 & 1 & 0 \\
\hline UKR & 0.029 & 0.029 & 0.329 & 0.395 & 0.02 & 0.008 & 0.014 & 0.067 & 1.987 & 0.993 & 0.993 & 2 & 0 & 0 & 0 & 1 & 0 \\
\hline URY & 0.044 & 0.029 & 0.356 & 0.4 & 0 & 0.022 & 0.008 & 0.106 & 2.111 & 0.704 & 0.493 & 3 & 0 & 0 & 0 & 0 & 0 \\
\hline USA & 0.015 & 0.015 & 0.325 & 0.36 & 0 & 0.006 & 0.004 & 0.003 & 1 & 1 & 1 & 1 & 0 & 0 & 0 & 0 & 0 \\
\hline UZB & 0.015 & 0.015 & 0.309 & 0.364 & 0 & 0.005 & 0 & 0.015 & 1 & 1 & 1 & 1 & 0 & 0 & 0 & 0 & 0 \\
\hline VEN & 0 & 0.015 & 0.2 & 0.366 & 0 & 0.001 & 0.007 & 0 & 1 & 1 & 1 & 1 & 0 & 0 & 0 & 0 & 0 \\
\hline
\end{tabular}


higher in/out degree than other countries, we can still derive some insightful information. Firstly, based on out-degree, China is the least central to the FEMTN network, with $C_{D_{\text {out }}}^{\mathrm{CHN}}=$ 0.191 suggesting they sell the least players within the network. More interestingly, the selling trade flow (out-degree) shows Brazil to be the most central $C_{D_{\text {out }}}^{\text {BRA }}=0.471$, which is larger than Turkey, $C_{D_{\text {out }}}^{\text {TUR }}=0.382$, and Russia, $C_{D_{\text {out }}}^{\text {RUS }}=0.309$, implying that Brazil is central to player sales within the emerging markets. Arguably, this aligns to footballs division of labour, as Brazil has long been considered producers of strong footballers in great quantities. Similarly, within the buying flow, China is the least central, $C_{D_{\text {in }}}^{\mathrm{CHN}}=0.353$, although it is considerably more than its in-degree, suggesting they concentrate on importing players over exporting players, which is perhaps part of a wider strategy. Unlike Brazil which is also central to the buying flow of trade within the emerging markets, $C_{D_{\text {in }}}^{B R A}=0.412$. However, Turkey, $C_{D_{\text {in }}}^{\text {TUR }}=$ 0.588 , is the most central to importing players within the FEMTN, followed by Russia, $C_{D_{\text {in }}}^{\text {RUS }}=$ 0.441 , suggesting Russia, and more so, Turkey are influential in terms of acquiring players in the FEMTN. Accepting that those with more connections have more power (Newman, 2008), then Brazil and Turkey, therefore, have the most seller and buyer power, respectively.

Within the emerging market's nodes, that is who our four countries are connected to through trade, there are signs of other countries taking central roles - albeit marginal to China, Brazil, Russia and Turkey. For example, Table 1 shows Portugal, Netherlands, Italy Germany and Argentina as all having the highest outdegree centrality, $C_{D_{\text {out }}}^{i}=0.059$, followed by a group of 12 countries (Uruguay, United Arab Emirates, Sweden, Poland, Japan, Iran, France, England, Spain, Czech Republic, Austria and Belgium) with an out-degree of $C_{D_{\text {out }}}^{i}=0.044$. This identifies two influential groups of countries, predominantly European, who are exporting players to the FEMTN, potentially taking advantage of the emerging markets football talent (resource). Conversely, there are less countries purchasing players from emerging market's with France taking a prominent central position $C_{D_{\text {in }}}^{F R A}=0.059$, followed by other European countries Bulgaria, Germany, Spain, England, Greece and Italy, with an in-degree, $C_{D_{\text {in }}}^{i}=0.044$. Again, it is the predominantly European countries who demonstrate a central role with the FEMTN. Seemingly, the top- 5 footballing countries globally, England, Spian, Germany, Italy and France, are consistently central to both flows of trade for the FEMTN, regardless of who is exploiting whom, it is clear that these countries have strategic positions within the network. That said, further research is needed, looking at the whole global football trade network to understand these strategic roles further. However, at this stage we see a complex structure emerging of trade between European traditional football trade markets and their relationship with emerging markets.

\section{Closeness centrality}

Another commonly observed endogenous nodal property is closeness centrality, which refers to topological distance, or how close a node is to all other nodes. This is an important concept as it shows how close countries are to each other, based on trade. Generally, distance in a network relates to the number of steps node $i$ requires to reach another node $j$, with the minimum path distance between $i$ and $j$ termed the geodesic distance. Inversing the average geodesic distance provides a proximity measure, with high scores showing nodes are closer to reachable nodes, noted as:

$$
C_{C}^{i}=\frac{(N-1)}{\sum_{j \neq i}^{N} \mathcal{D}_{i j}},
$$

with $\mathcal{D}_{i j}$ representing the geodesic distance between $i$ and $j$. If each country $i$ in the FEMTN is connected to all others, $\mathcal{D}_{i j}$ would 
equal 1, hence the less country $i$ is directly connected to nodes the smaller their closeness centrality. However, akin to degree centrality within a directed network, the geodesic distance for $i$ and $j$ may differ depending on the nodal order, for example, may not equal $\mathcal{D}_{j i}$. Therefore, in-closeness and out-closeness can be measured following:

$$
\begin{gathered}
C_{C_{\text {in }}}^{i}=\frac{(N-1)}{\sum_{j \neq i}^{N} \mathcal{D}_{j i}}, \\
C_{C_{\text {out }}}^{i}=\frac{(N-1)}{\sum_{j \neq i}^{N} \mathcal{D}_{i j}} .
\end{gathered}
$$

Out-closeness, or $C_{C_{\text {out }}}^{i}$ represents distance from export partners (buyers) and in-closeness, or $C_{C_{\text {in }}}^{i}$ represents distance from import partners (sellers).

Closeness centrality garners similar results as degree centrality but offers further support to our propositions within this paper. Brazil, $C_{C_{\text {out }}}^{B R A}$ $=0.422$ is most central to exporting players, with Turkey $\left(C_{C_{\text {in }}}^{\text {TUR }}=0.581\right)$ most central to importing players, based on proximity. However, China becomes substantially more central $C_{C_{\text {out }}}^{\mathrm{CHN}}=0.378$ and $C_{C_{\text {in }}}^{\mathrm{CHN}}=0.486$, with a significant increase in centrality for the selling flow. Thus, what this demonstrates is that if China wanted to increase its out-degree centrality, it has the network capability to do so. That said, the emerging market's alters have very similar out-closeness generally $C_{C_{\text {out }}}^{i}>0.3$, suggesting that China does not have much of a strategic position within the exporting market, but does have the network capacity to reverse this.

Within the buying market, however, there appears to be a group of European countries taking a more influential position than the rest, mainly France, $C_{C_{\text {in }}}^{\text {FRA }}=0.444$ followed by England, Spain, Germany and Greece, $C_{C_{\text {in }}}^{i}=$ 0.433 , and Italy, $C_{C_{\text {in }}}^{\text {ITA }}=0.422$. Very similar to degree centrality, the European elite - those countries with the top-5 leagues (Deloitte, 2017) - have an influential position on the FEMTN. This implies a European elite has the shortest paths - or are close - to the majority of other FEMTN countries, meaning they are able to take advantage of this when purchasing talent (assets). This may go some way to explaining why Europe is considered the most important part of the global football industry.

\section{Betweenness centrality}

Betweenness centrality is an indicator of prestige, referring to the extent to which node $i$ is involved in the geodesic distance of two unconnected nodes, $j$ and $k$. It is therefore essential to the indirect link between $j$ and $k$. This form of centrality has important strategic implications that can be exploited and leveraged for advantage. Thus, the betweenness centrality of country $i$ represents the proportion of geodesic distances $i$ is involved in indirectly connecting country $j$ and $k$ (Vega-Redondo, 2007). A standardised measure based on Freeman's (1978) idea is presented by De Benedictis and Tajoli (2011) as:

$$
C_{B}^{i}=\frac{\sum_{j \neq k} \frac{\mathcal{D}_{j k}^{i}}{\mathcal{D}_{j k}}}{(n-1)(n-2)}
$$

$C_{B}^{i}$ represents betweenness, $C_{B}$, for actor $i$, with $\mathcal{D}_{j k}$ noting the sum of geodesic distance between alters $j$ and $k$, and $\mathcal{D}_{j k}^{i}$ noting those geodesic distances between $j$ and $k$ involving $i$. Thus, a high $C_{B}$ measure suggests country $i$ trades with more unconnected trade partners, which can provide a strategic role within the network (structural hole). As the nodes are already ordered, then this measure does not provide separate in/out measures (Wasserman \& Faust, 2009).

Brazil and Turkey's apparent dominance within the FEMTN is more visible when exporting thus measure. Indeed, these two countries scores demonstrate the highest betweenness centrality out of the emerging market countries, $C_{B}^{B R A}=27.838$ and $C_{B}^{\text {TUR }}=25.525$. This demonstrates the powerful position these countries take within this network, as they are trading 
with unconnected partners, which means they occupy somewhat of a structural hole and act as a broker within the network (Burt, 1992). Interestingly, China's betweenness is comparatively low $C_{B}^{C H N}=9.191$, meaning it trades more with connected partners, reducing their importance within the network. This may evidence China's football strategy; that is, to create and maintain relations with well-connected or central countries. However, this may be considered counterproductive in that it weakens China's position in terms of leverage, at least following Burt's (1992) supposition.

Whilst it is expected that the emerging market countries have exponential values to other countries, there is a group of 16 countries, $C_{B}^{i}=0.02$, who are positioned between two unconnected trade partners - demonstrating that the FEMTN (hence China, Brazil, Turkey and Russia), are reliant on these countries to connect to the network, collectively providing influence and power. This not only includes the already established and dominant European countries but also, United Arab Emirates, Japan and Israel, among others. Again, this indicates each of these countries has an advantaged position in the network as they connect unconnected nodes.

\section{Structural holes}

As previously mentioned in this paper, the idea of betweenness underpins Burt's (1992) postulation of structural holes, which also forms part of Granovetter's structural embeddness framework. Burt proposed two extensions to the idea of betweenness; effect size and constraint. Effect size is based on the premise that if a node's alters are connected, then the node's connections are redundant. For example, if node $i$ is connected to node $j$ and $q-(i, j)$ and $(i, q)$, - but node $j$ is connected to $q(j, q)$ then $i$ 's connection to $j$ is redundant. Essentially effect size is based on the number of redundant ties an ego has. Whilst Burt (1992) provides detailed commentary, Borgatti (1997) supposed that redundancy is merely the number of alters a node has, minus the average degree of alters not including ties to that particular node, and therefore offers a simplistic alternative measure:

$$
\text { Redundency }=\frac{2 t}{n},
$$

where $t$ represents the number of ties in the network (not counting ties to ego) and $n$ denotes the number of nodes (excluding ego), which means effect size can be written;

$$
\text { EffectSize }=n-\frac{2 t}{n} .
$$

Furthermore, as this measure is contingent on degree, it can be normalised by dividing the effect size by the number of ties a node has, leading to what is termed efficiency (Borgatti et al., 2002; Hanneman \& Riddle, 2005). As a result of the boundary set from this study, the FEMTN efficiency metric is of more interest here, as naturally, the emerging market countries will have larger effect sizes. Also noteworthy, those with $100 \%$ efficiency are those peripheral countries, with only 1 trade partner which is again a result of the boundary construction, not necessarily exploitable position in the network.

What these measures do show us is that Turkey, China, Brazil and Russia are in dominant positions with $>90 \%$ efficiency, suggesting the majority of their trade partners do not trade with each other. It must be noted this is expected considering the boundary set for this network was China, Brazil Turkey and Russia, therefore we do not account for trade between other countries in this study. Nevertheless, out of the emerging market countries, Russia has the weakest position with $81 \%$ efficiency, demonstrating that $19 \%$ of Russia's football trade relations are redundant - as their trade partners also trade together, which is considerably lower than, Turkey, China and Brazil all with $>90 \%$ efficiency. Therefore, Turkey, China and Brazil are trading with partners who do not trade with each other meaning, Turkey, China and Brazil are more 
integral to their trade partners, giving them a slight advantage over Russia. In other words, China, Turkey and Brazil occupy structural holes within the network (Burt, 1992) meaning they have an exploitable position over Russia because their trade partners are more reliant on maintaining trade relations. Interestingly, Argentina (60\%), Austria (63\%), Bulgaria (61\%), Hungry (61\%), Serbia (60\%) and Netherlands $(65 \%)$ demonstrate some of the weakest positions as nearly $40 \%$ of their connections are redundant. This indicates these countries trade with countries who also trade with each other, meaning they have little leverage and are open to being exploited by other countries through paying inflated prices for players or selling players under value.

Burt's constraint idea is also concerned with the idea of redundancy and relates to how constrained a node is by the connection between alters in a node's neighbourhood. In other words, $i$ is constrained when $i$ has invested time and energy connecting with $j$, but then $j$ is surrounded by few structural holes, in that, $j$ has a relationship with $q$ in $i$ 's neighbourhood. Thus, $i$ does not have an exploitable position, as, if $i$ disconnects from $j$, then $j$ is still reachable by $q$. Mathematically, Burt's (1992, p. 55) Equation 2.4 is as follows:

$$
\operatorname{Con}_{i j}=\left(P_{i j}+\sum_{q} P_{i q} P_{q j}\right)^{2}, i \neq q \neq j,
$$

$P_{i j}$ relates to the proportional strength of i's relationship with $j$, and $P_{i q}$ denotes the strength of $i$ 's relationship with another $q$ where $P_{q j}$ depicts the strength of $q$ 's relationship with $j$. Here, the lower the constraint measure the less connected a node's alters are, or in this instance the less alternative trading partners. Accordingly, a country who is highly constrained means their trading partners are also trading, reducing the strategic position. Indeed, those who are totally constrained, 1, are the peripheral countries who had 100\% efficiency, again this is due to the boundary network set.

Again, similar to efficiency, Turkey, $\operatorname{Con}_{i j}=$ 0.216, and Brazil, Con ${ }_{i j}=0.207$, have the most exploitable position as they are least constrained by their trade partners, compared to China, $\operatorname{Con}_{i j}=0.258$, and Russia $\operatorname{Con}_{i j}=0.35$. This implies Turkey and Brazil trade with countries that have multiple structural holes, unlike Russia, which trades with countries with fewer structural holes. This once again highlights Russia's lack of strategic position within the FEMTN. Interestingly, looking at the European elite, Germany $\operatorname{Con}_{i j}=0.398$, Spain Con $_{i j}$ $=0.416$ and Italy Con $_{i j}=0.455$ have the most exploitable position $\operatorname{Con}_{i j}=0.398$, and are much less constrained than their counterparts, England $\operatorname{Con}_{i j}=.609$ and France $\operatorname{Con}_{i j}=0.622$. So whilst England and France show to be central to the FEMTN they do not have exploitable positions within the network - following Burt's thought on structural holes.

\section{Eigenvector centrality}

Proposed by Bonacich (1972a, 1972b) eigenvector centrality extends the notion of closeness centrality, however, this focuses on the closeness centrality (or geodesic distance) of node $i$ 's alters. Thus, it is a more sophisticated measure of closeness centrality as it assumes not all connections are equal - that is, connecting to an influential node (country) $j$ provides node (country) $i$ influence within the network, and as Newman (2008) formulated it can be expressed as:

$$
C_{E}^{i}=\frac{1}{\lambda} \sum_{j=1}^{n} A_{i j} x_{j}
$$

$C_{E}^{i}$ represents the eigenvector, $C_{E}$, for country $i$ where $\lambda$ is a constant - relating to the largest eigenvalue in the adjacency matrix. This measure shows the proportional centrality of country $i$ to the average of $i$ 's neighbourhood (connected alters), inferring that those 
connected to influential or powerful nodes are themselves influential.

Based on this notion of influential power within the network, China, $C_{E}^{C H N}=0.617$, is the most powerful. So whilst China has continuously shown a weaker position within the FEMTN based on their topological properties, they are connected to the more central countries than any other in the network. Russia, have a moderate eigenvector centrality, $C_{E}^{i}=0.42$, compared to, Brazil and Turkey, $C_{E}^{i}=$ 0.241 , who are not connected to other influential countries and therefore have low eigenvector centralities. This suggests that while China has not created an important position within the network, it has connected itself to the most central countries to garner power and influence. Interestingly, England occupies an advantageous position within the network $C_{E}^{\mathrm{GBR}}=0.454$, as it is connected to strongly connected others. Therefore, England is powerful within the FEMTN because it is connected to other high-trading countries.

\section{Bonacich power}

Whilst eigenvector centrality focuses on a node's alters' closeness centrality, Bonacich (1987) further proposed the notion of "dependency" referring to a node who's alters have a small degree - rather than a large degree has more power, because their alters are dependent on that connection. So based on this premise, if country $i$ is connected to country $j$ who is not well connected then country $i$ is more powerful because country $j$ is dependent on i. Generally, Bonacich's notation can be given (Borgatti et al., 2002)

$$
C_{P}^{i}=\sum_{i j}^{A}\left(\alpha+\beta C_{j}\right)
$$

$C_{p}^{i}$ represents the centrality power, $C_{p}$, of country $i$, with $\alpha$ being an arbitrary standardising constant. $\beta$ represents a positive or negative parameter - positive measures i's power based on well-connected alters (similar to that of eigenvector centrality) and negative measures i's power based on the dependency of low-connected alters. Thus, we followed the latter to establish which countries are most powerful in the FEMTN following Bonacich's work on dependency. However, the difficulty or problem with Bonacich's parameter $\beta$ is that it is researcher assigned (Scott, 2017); therefore we set the $\beta$ value as $1 /(n-1)$ following Borgatti et al. (2002), that is $1 / 69=0.01470588$, and because we are interested in who is powerful based on dependency then we assign -0.01470588 as the $\beta$ value. To follow the direction, the measure is worked out based on indegree and out-degree - that is who is connecting weakly connected nodes from buying (indegree) or selling (out-degree).

With regards to in-degree, Argentina, $C_{P_{\text {in }}}^{\text {ARG }}=$ -0.309 , is the weakest country in the network in relation to exporting players, because their trade partners all have high in-degree and are therefore buying players elsewhere. Hence, Argentina's selling power is low as their trade partners are not dependent upon them. However, this shifts when buying players, $C_{P_{\text {out }}}^{\text {ARG }}=0.284$, suggesting their trade partners have low out-degree and therefore are more dependent on Argentina to sell players. In terms of selling power within the network, European countries again demonstrate their influence, with Italy $C_{P_{\text {in }}}^{\text {ITA }}=0.598$, Spain $C_{P_{\text {in }}}^{\text {ESP }}=$ 0.434 and Portugal $C_{P_{\text {in }}}^{\mathrm{PRT}}=0.347$ having highly dependent alters, meaning they are connected to countries with a low number of trade partners to buy players from (in-degree). Arguably, Italy is an important node due to the country also having relative power $C_{P_{\text {out }}}^{\text {ARG }}=0.346$ in terms of buying power, as they are connected to countries with a low number of trade partners to sell player to (out-degree). Furthermore, France $C_{P_{\text {out }}}^{\text {FRA }}=0.639$, takes the most dominant position in terms of buying power, so their trade partners are reliant on their relationship with France to sell players, id est, they have minimal trade partners to sell to. Interestingly, England demonstrates the weakest position within the network regarding buyer power; 
indicating England's trade partners have multiple trade partners they sell players to, meaning they are not reliant on their trade relationship with England. This opens England up to exploitation, in that it can be leveraged economically for football talent, as trade partners can leverage England's weak position.

\section{Sub-groups and world systems}

The measures of centrality previously discussed in this paper are fundamentally about a countries position in the network and in that sense can be thought of as operating at the micro level of the network. However, as demonstrated by previous research (see Snyder \& Kick, 1979; and Kick et al., 2011) the actors (nodes) in a network, in this case countries, can be grouped together based on trading patterns. Essentially, regions and sub-groups within a network identify interconnected groups of nodes that can represent the underlying structure to the network. Indeed, this can occur at varying degrees; such as a clique - which is the strictest form of sub-group, as it requires each node to be connected to one another. There are multiple, less stringent, conceptualisations, n-cliques, n-clans, k-plexes - which all take a bottom-up approach (Hanneman \& Riddle, 2005) - which focus on the network from the beginning, or, evolving/emerging from a set of nodes tightly interconnected. However, they all have lesser stringent conditions. One of the most basic approaches to this is to partition the network based on differing densities, or degree, such as k-core which allows nodes to be involved in a clique even though they may not have to connections to every other node. Fundamentally, this partitions nodes are based on $k$ degree. Rather than provide statistical metrics here, we visualise it in Figure 2.

The FEMTN has three groups of countries within the network. Firstly, there is a central group of countries, the core, naturally made up of the four ego's, China, Brazil, Turkey, Russia, as well as - and most interesting here
- those central European countries, Spain, Italy, England, France, Germany, Portugal, Netherland, Poland, Greece, along with Argentina. These countries are interlinked but also link to other groups, such as the semi-periphery, that is those countries which trade with the core countries, but not the periphery. This is made up of Middle Eastern countries - like Saudi Arabia, Israel, Azerbaijan and Iran - Asian countries, such as Korea (South), Japan, and Thailand, South American countries Chile, Mexico and Columbia, as well as, other European countries, such as Sweden, Switzerland, Denmark, Czech Republic and Norway. The final group - the periphery - represents the outer layer countries who only trade with the core, and not the other members of the periphery. This is generally made up of countries where football is less developed, such as, Egypt, Qatar, United States of America, Kazakhstan, Iraq, Ethiopia, Latvia, among others.

Interestingly, using $k$-core to partition the FEMTN reveals a world-systems network that is comparable with the output of Kick et al. (2011), and the ideas of Wallerstein (1974a; 1974b) which demonstrated that developed core nations exploit underdeveloped peripheral countries. Whilst we do not provide the same level of analysis as Kick et al., who utilise a more sophisticated block modelling approach, we nevertheless assert that in general those countries where the football market is more developed, including the emerging markets, countries form a core which ultimately use their position within the network to exploit less developed countries (in a football sense).

\section{Brokerage}

Since the $k$-core produces categorical data, this allows us to investigate brokerage of the emerging market countries within the FEMTN. Along with structural holes, Burt (1992) also used brokerage to understand how an actor is embedded within a network; the notion is similar to betweenness in that it focuses on an 


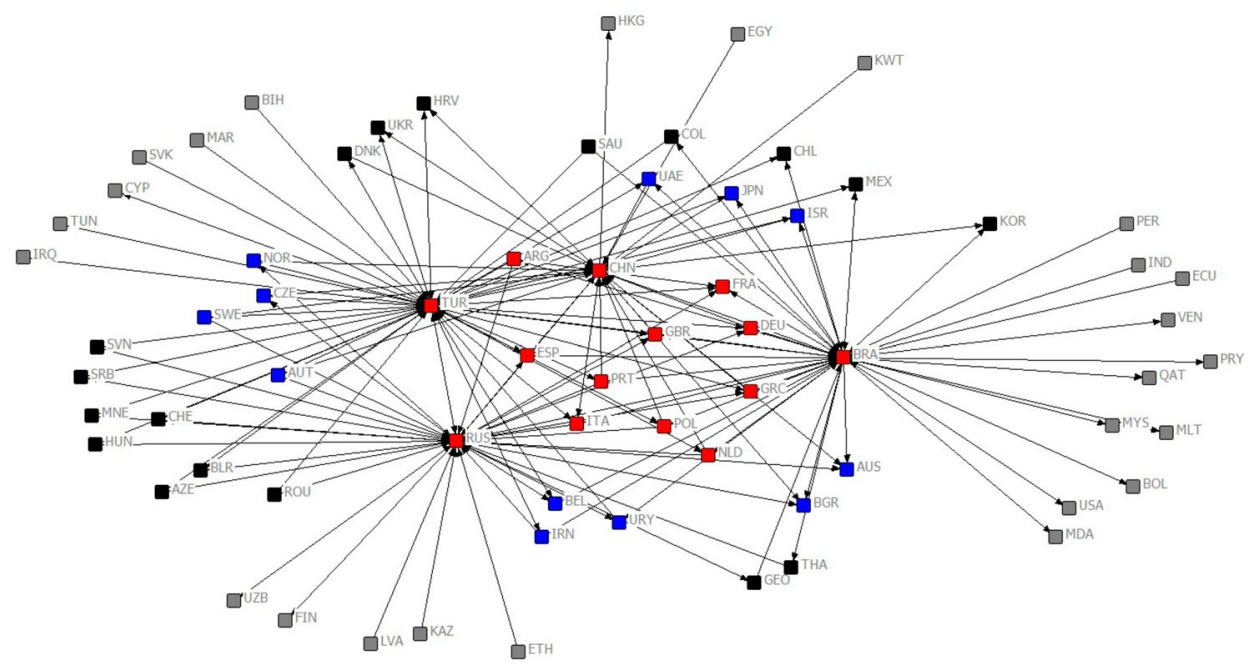

Figure 2. K-core of the football's emerging markets trade network.

actor's role in connecting two unconnected actors. Similarly, Gould and Fernandez (1989) also looked at the brokerage but focused on an actor's role within its neighbourhood or between groups. In doing so, they provide 5 measures based on the role $i$ plays in connecting $j$ and $k$, depending on the groups these nodes belong. Their measures count how many times $i$ is a broker to $j$ and $k$ when: all nodes belong to the same group $(j=i=k)$ known as Coordinator; $i$ is not part of the same group but $j$ and $k$ are $(j=k \neq i)$ - known as Consultant; $j$ is not part of the same group but $i$ and $k$ are $(j \neq i=k)$ - known as Gatekeeper; $k$ is not part of the same group but $i$ and $j$ are $(j$ $=i \neq k)$ - known as Representative; and when all nodes belong to a different group $(j \neq i \neq k)-$ known as Liasion. For this analysis, we used the categorical data provided by the $k$-core analysis.

Whilst there are more sophisticated measures, we simply use the count of each time a country acts as a broker. Table 1 presents the scores. Out of the emerging market countries, Turkey and Brazil act as a broker more so than China and Russia in each scenario. In terms of the coordinator role, Turkey brokers trade relations 97 times within the network, implying they - along with Brazil (79) - are the main brokers within the core. Once more, this identifies Turkey and Brazil being the most central and influential countries in the network. Indeed, Brazil and Turkey broker more relations connecting each of the groups; Turkey plays the gatekeeper role 278 times and Brazil 221, connecting the (semi) periphery groups to the core and alternatively connecting the core to the (semi) periphery through the representative role. More importantly, the two countries are essential in connecting the periphery to the semi-periphery, playing the liaison role 394 (Turkey) and 331 (Brazil) times, respectively. Given China's rise in terms of football, and their vision for its future, it is surprising that China does not have a more influential role, having minimal brokerage compared to Turkey and Brazil. This probably reflects on the immaturity of China's football strategy compared to the other countries under investigation.

\section{Discussion}

Evidently, applying network analysis to the football trade network, such as the emerging markets, yields some interesting insights. At 
the very basic level - such as (in)out-degree - it is clear Brazil and Turkey have distinct roles within the network, Brazil predominantly sells players and Turkey predominantly buys players. Although they are both central in terms of selling and buying, this arguably follows Heckscher-Ohlin theorem in that, Brazil are exporting a labour-intensive product - footballing talent. Interestingly, however, following the same logic, China or Russia would represent the capital rich countries and therefore would be expected to be integral to the buying market, yet this is Turkey. Though this makes more sense from a world-systems approach, in that, Turkey being the most developed football country (out of China, Russia and Brazil) exploits the less football developed emerging countries China, Russia and Brazil (Wallerstein, 1974a, 1974b). Further to this, when applying k-core to the FEMTN, it identifies sub-groups akin to that of world-systems, very similar to the core, semi-periphery and periphery findings of Snyder and Kick (1979) and Kick et al. (2011). Therefore, showing how football trade follows a similar global structure to other relations as normal trade, diplomatic relations and military alliances, supporting Granovetter's $(1985,2017)$ embeddedness argument. Indeed, this needs to be further explored within the football transfer market, and future research should focus on advanced network analysis such as block modelling and equivalence analysis in-line with Kick et al. (2011) extensive work.

China's role - or lack of - within the FEMTN is somewhat surprising, given the emphasis on their football strategy and football investment. However, this is a potential result of their strategy of investing - potentially over investing - in European football. This is evident through their superior eigenvector score, showing they are well connected to other well-connected or central countries. Whilst this can provide power as they are connected to well-connected (powerful) countries, it means they lack exploitable advantageous positions such as being connected to less-connected (weak) countries, which are mainly occupied by Brazil and Turkey. Thus Brazil and Turkey derive power by developing dependency through trading with poorly connected countries, whereas China garner power through trading with wellconnected countries. Perhaps this is a consequence of a strategic policy to grow the game internally. Consequently, their investment in creating and maintaining strategic connections with central countries has resulted in neglecting other, arguably more exploitable, positions in the network, such as brokerage (Burt, 1992). That said, China's strategy is not due to lack of access to the network, they have the capacity to change their position, as they are central from a closeness perspective, meaning they have the proximity to poorly connected countries. If they were to do so this would drastically improve their leverage within the global transfer market.

Brazil and Turkey have clearly adopted a different strategy to China, creating powerful and influential positions within the FEMTN, especially in relation to occupying structural holes, meaning they broker the majority of relations throughout the network, aligning to Burt's (1992) argument. Especially in terms of their brokerage roles of not only connecting the core (coordinator) but more importantly connecting the periphery to the semi-periphery (liason), following Gould and Fernandez (1989). Therefore, they have very strategic roles providing power and influence over the different groups within the network. This may go some way to explain their rise as global football powerhouses, which if they further exploit their positions they can dominate the emerging markets.

The power and influence of European countries are evident, especially the top-5 leagues, England, France, Italy, Germany and Spain (Deloitte, 2017). However, they all have interchangeable advantageous positions throughout the network. For example, taking the traditional view of power being inferred 
by being connected to high-trading countries (eigenvector centrality), England has the most powerful position. Yet akin to China, this is somewhat counterproductive for England as they are highly constrained (Burt, 1992), because they trade with high-trading countries, meaning their partners also trade with each other, reducing England's power - as less of the partners need England to trade. Indeed, England is considered the nucleus of European football (Deloitte, 2017), however, this finding suggests if this was to change, England would not hold a very exploitable position within emerging markets. This is further compounded taking the alternative view that power comes from trading with low-trading countries (Bonacich, 1987) - because they are more dependent on maintaining that connection, thus exploitable. England is very weak, mainly because not many of their trading partners are reliant on their relationship, meaning England are susceptible to being exploited themselves - which may explain the rise in transfer expenditure of top-flight English clubs, which is considerably more than the other top-5 European leagues (Deloitte, 2017). To this end, English clubs should concentrate their efforts on acquiring talent from less powerful countries, similar to that of France, Spain and Portugal, whose trading partners are reliant on their trade, thus reducing the likelihood of exploitation.

Nevertheless, the continuing importance of the European elite, such as England, Spain and France within FEMTN is likely to be bound-up in colonial history, as well as language, culture and prevailing norms, demonstrating an empirical example of Granovetter's (1985, 2017) embeddedness. This structure provides trust throughout the network - that is, emerging markets trust the European elite in trade deals. In a similar vein, the football transfer network is embedded in various other network structures: sporting, industrial, institutional and political. For example, China's reliance on powerful footballing trade partners for their talent supply-chain may reflect their state backed football strategy.

From a management perspective, it is apparent countries need to be conscious of the investment/recruitment strategies influence on network structure and position. For example, Russian professional clubs have repeatedly demonstrated a predisposition towards signing Brazilian players, while its own domestic talent has evidently not been inclined to move overseas. Whilst in China, the government has significantly restricted the flow of overseas players into the country at the same time as encouraging young domestic players to move overseas to gain experience. Additionally, identification, selection and maintenance of footballing resource supply-chain, are important considerations industry leaders need to be aware of, especially in terms of over reliance on important and influential countries.

\section{Concluding Remarks}

Whilst we have sought to capture and present the dynamic nature of the football player transfer network in this paper, such an analysis is inevitably somewhat static in nature. Undertaking further work on a longitudinal basis would partly address this, and provide insight to understand how such networks evolve and change over time. That said, we have presented an exploratory, and to some degree, within sport management literature, a novel investigation into the football transfer from a trade network perspective, set in the context of economic sociology. Whilst there are several limitations in the approach adopted by this paper, not least, the boundary set for the network is based on four countries; we have shown how the position within the football trade network can be exploited, thus clubs, countries and in some cases governments can be strategic in their footballing endeavours.

We demonstrate that the football transfer network follows a similar structure to that of normal trade, political and international 
relations. However, future research should focus on the whole network global transfer market to provide better insight to the network structure and topological properties of countries, to establish if the world-systems perspective also holds true - ideally using blockmodeling or similar equivalence methods. Similarly, a direct followup study should analyse the relationship between network position and football talent investment, ideally at a club level. This can help ascertain if network positions can lead to a tendency to be exploited within the football transfer market, as well as providing much needed insight into strategic alliances between football clubs internationally and/or domestically.

As well as functional applications, (social) network analysis can also be used for more critical applications such as, understanding the role that countries from Africa or South America play within the overall network; especially as migration or muscle drain is a major concern for the development of their internal football structures.

In practical terms, it is important that officials within the football industry acknowledge and embrace the need to adopt appropriate approaches to managing with networks. This not only implies a need to understand the connected, embedded nature of transfer activity, it also suggests the need to develop competence in the field. For example, issues of partner identification, acquisition and management would appear to be an imperative. Similarly, the significance of boundary management, collaborating to compete and creating sustainable labour supply-chains are pertinent outcomes of this research. Finally, researchers and practitioners will hopefully find use in the methods and findings from this paper to understand how clubs and countries can use trade partners advantageously for leverage and potentially, growth.

\section{Disclosure statement}

No potential conflict of interest was reported by the author(s).

\section{References}

Aldrich, J. (2004). The discovery of comparative advantage. Journal of the History of Economic Thought, 26(3), 379-399.

Almog, A., Squartini, T., \& Garlaschelli, D. (2017). The double role of GDP in shaping the structure of the international trade network. International Journal of Computational Economics and Econometrics, 7(4), 381-398.

Arthur, W. B. (1999). Complexity and the economy. Science, 284(5411), 107-109.

Bargigli, L., \& Gallegati, M. (2011). Random digraphs with given expected degree sequences: A model for economic networks. Journal of Economic Behavior \& Organization, 78(3), 396-411.

Baskaran, T., Blöchl, F., Brück, T., \& Theis, F. J. (2011). The Heckscher-Ohlin model and the network structure of international trade. International Review of Economics \& Finance, 20(2), 135-145.

Bastian, M., Heymann, S., \& Jacomy, M. (2009). Gephi: An open source software for exploring and manipulating networks. International AAAl conference on weblogs and social media.

Bonacich, P. (1972a). Factoring and weighting approaches to status scores and clique identification. The Journal of Mathematical Sociology, 2(1), 113-120.

Bonacich, P. (1972b). Technique for analyzing overlapping memberships. Sociological Methodology, 4, 176-185.

Bonacich, P. (1987). Power and centrality: A family of measures. American Journal of Sociology, 92(5), 1170-1182.

Borgatti, S. P. (1997). Structural holes: Unpacking Burt's redundancy measures. Connections, 20(1), 35-38.

Borgatti, S. P., Everett, M. G., \& Freeman, L. C. (2002). Ucinet 6 for Windows: Software for social network analysis. Harvard, MA: Analytic Technologies.

Borgatti, S. P., \& Halgin, D. S. (2011). On network theory. Organization Science, 22(5), 1168-1181.

Bornschier, V., \& Chase-Dunn, C. (1985). Transnational corporations and underdevelopment. New York, NY: Praeger.

Brander, J., \& Krugman, P. (1983). A "reciprocal dumping" model of international trade. Journal of International Economics, 15(3-4), 313-321.

Burt, R. (1992). Structural holes: The social structure of competition. Cambridge, MA: Harvard University Press.

Cartwright, D., \& Harary, F. (1977). A graph theoretic approach to the investigation of system-environment relationships. The Journal of Mathematical Sociology, 5(1), 87-111. 
Chase-Dunn, C., \& Grimes, P. (1995). World-systems analysis. Annual Review of Sociology, 21(1), 387417.

Chipman, J. S. (1965a). A survey of the theory of international trade: Part 1 , the classical theory. Econometrica, 33(3), 477-519.

Chipman, J. S. (1965b). A survey of the theory of international trade: Part 2, The neo-classical theory. Econometrica, 33(4), 685760.

Coase, R. H. (1960). The problem of social cost. The Journal of Law and Economics, 3(1), 1-44.

De Benedictis, L., Nenci, S., Santoni, G., Tajoli, L., \& Vicarelli, C. (2014). Network analysis of world trade using the BACI-CEPII dataset. Global Economy Journal, 14(3-4), 287-343.

De Benedictis, L., \& Tajoli, L. (2011). The world trade network. The World Economy, 34(8), 14171454.

Deloitte. (2017). Deloitte Football Money League 2017, Deloitte. Retrieved from https://www2.deloitte. com/uk/en/pages/sports-business-group/articles/ deloitte-football-money-league.html

Durkheim, E. (1984). The division of labor in society. New York, NY: Free Press.

Fagiolo, G., Reyes, J., \& Schiavo, S. (2009). World-trade web: Topological properties, dynamics, and evolution. Physical Review E, 79(3), 036115. https://doi. org/10.1103/PhysRevE.79.036115

Fagiolo, G., Reyes, J., \& Schiavo, S. (2010). The evolution of the world trade web: A weightednetwork analysis. Journal of Evolutionary Economics, 20(4), 479-514.

FIFA. (2017a). FIFA TMS Global Trnasfer Market 2017: record international transfers in 2016, FIFA.com. Retrieved from http://www.fifa.com/governance/ news $/ y=2017 / \mathrm{m}=1 /$ news=fifa-tms-global-transfermarket-2017-record-international-transfers-in2865353.html

FIFA. (2017b). FIFA TMS Data \& Reports, FIFA.com. Retrieved from https://www.fifatms.com/datareports

FIFA. (2017c). Global Transfer Market Report 2017, FIFA.com. Retrieved from https://www.fifatms. com/data-reports/reports

Frank, A. G. (1966). The development of underdevelopment (pp. 76-84). Boston, MA: New England Free Press.

Freeman, L. C. (1978). Centrality in social networks conceptual clarification. Social networks, 1(3), 215-239.

Fronczak, A., \& Fronczak, P. (2012). Statistical mechanics of the international trade network. Physical Review E, 85, 056113. https://doi.org/10.1103/ PhysRevE.85.056113
Garlaschelli, D., Di Matteo, T., Aste, T., Caldarelli, G., \& Loffredo, M. I. (2007). Interplay between topology and dynamics in the world trade Web. European Physical Journal B-Condensed Matter, 57(2), 159164.

Garlaschelli, D., \& Loffredo, M. I. (2004). Fitness-dependent topological properties of the world trade web. Physical Review Letters, 93(18), 188701. https://doi.org/10.1103/PhysRevLett.93.188701

Garlaschelli, D., \& Loffredo, M. I. (2005). Structure and evolution of the world trade network. Physica $A$ : Statistical Mechanics and its Applications, 355(1), 138-144.

Gould, R. V., \& Fernandez, R. M. (1989). Structures of mediation: A formal approach to brokerage in transaction networks. Sociological Methodology, 19, 89-126.

Goyal, S. (2012). Connections: An introduction to the economics of networks. New Jersey: Princeton University Press.

Granovetter, M. (1985). Economic action and social structure: The problem of embeddedness. American Journal of Sociology, 91(3), 481-510.

Granovetter, M. (2005). The impact of social structure on economic outcomes. Journal of Economic Perspectives, 19(1), 33-50.

Granovetter, M. (2017). Society and economy: Framework and principles. Cambridge: Harvard University Press.

Hanneman, R. A., \& Riddle, M. (2005). Introduction to social network methods. Riverside, CA: University of California, Riverside. Retrieved from http:// faculty.ucr.edu/ hanneman

Heckscher, E. (1919). The effect of foreign trade on the distribution of income. Ekonomisk Tidskrift, $X X I$, 497-512. (Reprinted in Readings in the Theory of International Trade, Blakiston, Philadelphia, 1949).

Ito, T., Rotunno, L., \& Vézina, P. L. (2017). HeckscherOhlin: Evidence from virtual trade in value added. Review of International Economics, 25(3), 427-446.

Jackson, M. O. (2010). Social and economic networks. Oxford: Princeton university press.

Jackson, M. O. (2014). Networks in the understanding of economic behaviors. Journal of Economic Perspectives, 28(4), 3-22.

Jones, R. W. (1956). Factor proportions and the Heckscher-Ohlin theorem. The Review of Economic Studies, 24(1), 1-10.

Kali, R., \& Reyes, J. (2007). The architecture of globalization: A network approach to international economic integration. Journal of International Business Studies, 38(4), 595-620. 
Kali, R., \& Reyes, J. (2010). Financial contagion on the international trade network. Economic Inquiry, 48 (4), 1072-1101.

Kearney, A. T. (2011). The Sports Market. Major Trends and Challenges in an Industry. Retrieved from http://www.atkearney.co.uk/documents/10192/ 259371/Sports_Market.pdf/6f46b880-f8d1-49099960-cc605bb1ff34

Kick, E, L, McKinney, L, A, McDonald, S, \& Jorgenson, A. (2011). A Multiple-Network Analysis of the World System of Nations, 1995-1999. In John Scott, \& Peter CarringtonJ (Eds.), The SAGE Handbook of Social Network Analysis (pp. 311-328). London: SAGE Publications Ltd.

Knoke, D. (2012). Economic networks. Polity Press: Cambridge.

Knoke, D. \& Yang, S. (2008). Social network analysis (p. 154). London: Sage.

Kranton, R. E., \& Minehart, D. F. (2001). A theory of buyer-seller networks. American Economic Review, 91(3), 485-508.

Krugman, P. R. (1979). Increasing returns, monopolistic competition, and international trade. Journal of International Economics, 9(4), 469-479.

Lin, N. (2002). Social capital: A theory of social structure and action (Vol. 19). Cambridge: Cambridge University Press.

Liu, X. F., Liu, Y.-L., Lu, X.-H., Wang, Q.-X., \& Wang, T.-X. (2016). The anatomy of the global football player transfer network: Club functionalities versus network properties. PLOS ONE, 11(6), e0156504. https://doi.org/10.1371/journal.pone.0156504.

Maratea, A., Petrosino, A., \& Manzo, M. (2016). Triadic motifs in the partitioned world trade web. Procedia Computer Science, 98, 479-484.

Massey, D. S., Arango, J., Hugo, G., Kouaouci, A., Pellegrino, A., \& Taylor, J. E. (1993). Theories of international migration: $A$ review and appraisal. Population and Development Review, 19(3), 431466.

Moreno, J. L. (1932). Application of the group method to classification. New York, NY: National Committee on Prisons and Prison Labor.

Moreno, J. L. (1934). Who shall survive? Washington, DC: Nervous and Mental Disease Publishing Company.

Morrow, S. (1996). Football players as human assets. Measurement as the critical factor in asset recognition: A case study investigation. Journal of Human Resource Costing \& Accounting, 1(1), 75-97.

Nemeth, R. J., \& Smith, D. A. (1985). International trade and world-system structure: A multiple network analysis. Review (Fernand Braudel Center), 8(4), 517-560.
Newman, M. E. (2008). The mathematics of networks. The new Palgrave encyclopedia of economics. Retrieved from http://www-personal.umich.edu/ mejn/papers/palgrave.pdf

Ohlin, B. (1933). Interregional and international trade. Cambridge: Harvard University Press.

Plunket Research. (2017). Sports industry statistics and market size overview. Sport \& Recreation Business Statistics Analysis. Retrieved from https:// www.plunkettresearch.com/statistics/sportsindustry

Posner, M. V. (1961). International trade and technical change. Oxford Economic Papers, 13(3), 323-341.

Ricardo, D. ([1817] 1951). On the principles of political economy, and taxation. London: John Murray. In Sraffa, P. (Eds.) The Works and Correspondence of David Ricardo, Vol I. Cambridge University Press: Cambridge.

Ruffin, R. J. (2005). Debunking a myth: Torrens on comparative advantage. History of Political Economy, 37(4), 711-722.

Sarajlić, A., Malod-Dognin, N., Yaveroğlu, ÖN, \& Pržulj, N. (2016). Graphlet-based characterization of directed networks. Scientific Reports, 6, 35098 . doi:10.1038/srep35098

Scott, J. (2017). Social network analysis. Sage: London.

Serrano, M. A., \& Boguná, M. (2003). Topology of the world trade web. Physical Review E, 68(1), 015101 (R). https://doi.org/10.1103/PhysRevE.68.015101

Simmel, Georg. ([1922] 1955). Conflict and the Web of group affiliations. (K. H. Wolff and R. Bendix Trans.).New York, NY: Free Press.

Simon, H. A. (1955). A behavioral model of rational choice. The Quarterly Journal of Economics, 69(1), 99-118.

Smith, A. ([1776] 1937). An inquiry into the nature and causes of the wealth of nations. Edwin Cannan (Ed.). NewYork, NY: Modern Library.

Snyder, D., \& Kick, E. L. (1979). Structural position in the world system and economic growth, 19551970: A multiple-network analysis of transnational interactions. American Journal of Sociology, 84(5), 1096-1126.

Squartini, T., Fagiolo, G., \& Garlaschelli, D. (2011a). Randomizing world trade. I. A binary network analysis. Physical Review E, 84(4), 046117. https:// doi.org/10.1103/PhysRevE.84.046117

Squartini, T., Fagiolo, G., \& Garlaschelli, D. (2011b). Randomizing world trade. II. A weighted network analysis. Physical Review E, 84(4), 046118. https:// doi.org/10.1103/PhysRevE.84.046118

Therien, J. P. (1999). Beyond the north-south divide: The two tales of world poverty. Third World Quarterly, 20(4), 723-742. 
Thweatt, W. O. (1976). James Mill and the early development of comparative advantage. History of Political Economy, 8(2), 207-234.

Vega-Redondo, F. (2007). Complex social networks (No. 44). Cambridge: Cambridge University Press.

Wallerstein, I. (1974a). The modern world system: Capitalist agriculture and the origins of the European world economy in the sixteenth century. New York, NY: Academic Press, USA.

Wallerstein, I. (1974b). The rise and future demise of the world capitalist system: Concepts for comparative analysis. Comparative Studies in Society and History, 16(4), 387-415.

Wallerstein, I. M. (2004). World-systems analysis: An introduction. Durham: Duke University Press.

Wasserman, S., \& Faust, K. (2009). Social network analysis: Methods and applications (19th Ed.). New York: Cambridge University Press.

Wilhite, A. (2001). Bilateral trade and "small-world" networks. Computational Economics, 18(1), 49-64.

Zhang, X. (2017). Chinese capitalism and the maritime silk road: A world-systems perspective. Geopolitics, 22(2), 310-331. 